\title{
MiR-2I-5p promotes the progression of non-small-cell lung cancer by regulating the expression of SMAD7
}

This article was published in the following Dove Press journal:

OncoTargets and Therapy

\author{
Xiangpan $\mathrm{Li}^{1}$ \\ Xiaofei $\mathrm{Wu}^{2}$ \\ 'Department of Oncology, Renmin \\ Hospital of Wuhan University, \\ Wuchang, Wuhan, Hubei Province, \\ People's Republic of China; \\ 2Department of Neurology, Chinese \\ People's Liberation Army, Wuhan \\ General Hospital, Wuchang District, \\ Wuhan, Hubei Province, People's \\ Republic of China
}

Objective: The objective of this study was to detect the expression of MiR-21-5p in non-smallcell lung cancer (NSCLC) tissues, and to investigate the effect of its expression on the progression of NSCLC.

Methods: Real-time fluorescent quantitative PCR was used to detect the relative expression of MiR-21-5p in 118 NSCLC tumor tissues to their adjacent normal tissues. The expressions of SMAD7, MMP-9, E-cadherin, and vimentin proteins were detected by Western blotting or immunohistochemistry. Cell colony formation, scratch, and Transwell assays were used to detect the proliferation, migration, and invasion ability of A549 cells, respectively.

Results: MiR-21-5p was highly expressed in the tumor tissues of NSCLC patients, and its expression was significantly correlated with the clinical classification of NSCLC patients $\left(\chi^{2}=7.154\right.$, $P=0.007)$, tumor size $\left(\chi^{2}=4.372, P=0.037\right)$, differentiation $\left(\chi^{2}=13.713, P=0.001\right)$, lymph node metastasis $\left(\chi^{2}=5.101, P=0.024\right)$, distant metastasis $\left(\chi^{2}=12.599, P=0.000\right)$, and TNM stage $\left(\chi^{2}=6.344, P=0.012\right)$, whereas it was positively correlated with the expression of SMAD7 protein ( $r=0.669, P<0.05$ ). The results of the luciferase gene reporter system showed that MiR-21-5p targeted and promoted the expression of SMAD7 gene, which enhanced NSCLC cell proliferation. Furthermore, MiR-21-5p promoted the expressions of MMP-9 and vimentin proteins as well as inhibited the expression of E-cadherin protein, which is associated with an elevated SMAD7 protein expression and enhanced the invasion/migration ability of NSCLC cells.

Conclusion: MiR-21-5p was highly expressed in NSCLC tumor tissues, and its high expression could promote NSCLC progression by targeting the expression of SMAD7.

Keywords: MiR-21-5p, SMAD7, non-small-cell lung cancer, progression, MMP-9, E-cadherin

\section{Introduction}

Lung cancer, including both small-cell lung cancer and non-small-cell lung cancer (NSCLC), is the leading cause of death in patients with malignant tumors in the People's Republic of China, and $>80 \%$ of lung cancer patients are diagnosed with NSCLC. ${ }^{1,2}$ Because patients with NSCLC do not have characteristic clinical symptoms in the early stage, they are generally diagnosed in a middle or late stage, with extremely low postoperative survival rate. ${ }^{3}$ Therefore, it is of great significance to study the molecular mechanism of the genesis and progression of NSCLC in order to develop targeted drugs as well as prolong the postoperative survival period for NSCLC patients.

MicroRNAs are a type of single-strand noncoding RNA encoded by 20-25 nucleotides, which modulate cell proliferation, differentiation, apoptosis, metabolism, and invasion/migration by targeted regulation of gene expression at both transcription and translation levels. ${ }^{4,5}$ MicroRNAs not only serve as biomarkers for the diagnosis
Correspondence: Xiaofei Wu Department of Neurology, Chinese People's Liberation Army, Wuhan General Hospital, 627 Wuluolu Street, Wuchang District, Wuhan, Hubei Province, People's Republic of China Tel +86278804 I9l I Email wuxiaofwhgh@I63.com
8445 
of many diseases but also play an important role in disease genesis and progression. ${ }^{6}$ In recent years, a number of studies ${ }^{7,8}$ have shown that the occurrence and development of NSCLC are related to the abnormal expression of miRNAs. Previous studies ${ }^{9}$ have verified that MiR-21-5p is abnormally expressed in NSCLC tissues; however, the effect of abnormal expression of MiR-21-5p on the progression of NSCLC has not been thoroughly explored. In this study, we detected the expression level of MiR-21-5p in the tumor tissues and the adjacent normal tissues of NSCLC patients by real-time quantitative PCR, and analyzed its relationship with clinical and pathological data of NSCLC patients to investigate the effect of its expression on the progression of NSCLC.

\section{Materials and methods}

\section{General materials}

In total, 118 pairs of tumor tissues and the adjacent normal tissues ( $\geq 5 \mathrm{~cm}$ ) of NSCLC patients who underwent surgery from January 2012 to June 2015 were collected. All of the 118 cases of NSCLC were confirmed by clinical pathology, and two pathologists independently conducted the histological review to identify the tumors and adjacent tissues. There were 72 male patients and 46 female patients, between 45 and 70 years of age. Other clinical data are shown in Table 1. All the patients provided informed consent to donate their

Table I Clinical data of the 1 I 8 cases of NSCLC patients

\begin{tabular}{|c|c|c|}
\hline Item & Case (n) & Account (\%) \\
\hline \multicolumn{3}{|l|}{ Gender } \\
\hline Male & 72 & 61.02 \\
\hline Female & 46 & 38.98 \\
\hline \multicolumn{3}{|l|}{ Age (years) } \\
\hline$\geq 60$ & 50 & 42.37 \\
\hline$<60$ & 68 & 57.63 \\
\hline \multicolumn{3}{|l|}{ Clinical classification } \\
\hline Squamous cell carcinoma & 42 & 35.60 \\
\hline Adenocarcinoma & 76 & 64.40 \\
\hline \multicolumn{3}{|l|}{ Tumor size $(\mathrm{cm})$} \\
\hline$\leq 5$ & 51 & 43.22 \\
\hline$>5$ & 67 & 56.78 \\
\hline \multicolumn{3}{|l|}{ Degree of differentiation } \\
\hline Well differentiated & 22 & 18.64 \\
\hline Moderately differentiated & 39 & 33.05 \\
\hline Poorly differentiated & 57 & 48.31 \\
\hline \multicolumn{3}{|l|}{ Lymph node metastasis } \\
\hline Metastasis & 73 & 61.86 \\
\hline No metastasis & 45 & 38.14 \\
\hline \multicolumn{3}{|l|}{ Distant metastasis } \\
\hline Metastasis & 69 & 58.47 \\
\hline No metastasis & 49 & 41.53 \\
\hline \multicolumn{3}{|l|}{ TNM stage } \\
\hline $\mathrm{I}+\mathrm{II}$ & 38 & 32.20 \\
\hline III+IV & 80 & 67.80 \\
\hline
\end{tabular}

tissues in a prospective study before undergoing surgery. This research was approved by the ethics committee of Wuhan General Hospital Affiliated to the Chinese People's Liberation Army.

\section{Real-time fluorescent quantitative PCR}

Total tissue RNA was extracted by a total tissue RNA extraction kit (Beyotime Biotechnology, People's Republic of China) and reverse-transcribed into cDNA by All-in-One ${ }^{\mathrm{TM}}$ miRNA First-Strand cDNA Synthesis Kit (GeneCopoeia Inc., Germantown, MD, USA). The RNA was harvested from frozen specimens that were stored at $-80^{\circ} \mathrm{C}$ following surgical resection. The expression level of MiR-21-5p (reverse primer: $5^{\prime}$ CTCAACTGGTGTCGTGGAGTCGGCAATTCAGT TGAGGATTATGA-3'; forward primer: 5'-ACACTCCA GCTGGGTAGCTTATCAGACTGA-3') and U6 (reverse primer: 5'-AACGCTTCACGAATTTGCGT-3'; forward primer: 5'-CTCGCTTCGGCAGCACA-3') were detected by an miRNA-qPCR kit (GeneCopoeia Inc.) and real-time fluorescence quantitative PCR instrument (Agilent Technologies, Santa Clara, CA, USA). The results were presented as $2^{-\Delta \Delta \mathrm{Ct}}\left(\Delta \Delta \mathrm{Ct}=\Delta \mathrm{Ct}_{\text {tumor }}-\Delta \mathrm{Ct}_{\text {adjacent }} ; \Delta \mathrm{Ct}=\mathrm{Ct}_{\mathrm{MiR}-21-5 \mathrm{p}}-\mathrm{Ct}_{\mathrm{U} 6}\right)$. The unit of expression of MiR-21-5p in tumor tissues is given in fold change and is compared to adjacent normal tissues.

\section{Immunohistochemistry}

The preserved paraffin sections were subjected to immunohistochemical analysis according to the manufacturer's instructions in the Dako LSAB2 universal immunohistochemical kit (Beijing Biolead Technology Development Co., Ltd., Beijing, People's Republic of China) with SMAD7 mouse monoclonal antibody (Santa Cruz Biotechnology, Santa Cruz, CA, USA) as the primary antibody (PBS was used as the negative control). The SMAD7 protein was expressed in the cytoplasm, and its positive expression by immunohistochemical staining was recognized as pale-brown granules or clusters in the cytoplasm. The immunohistochemical results were analyzed by HPIAS 2000 software, and the scoring criteria were shown in Table 2. The score for the expression of SMAD in each specimen $\mathrm{X}=$ score of positive cell rate $\times$ score of absorbance,

Table 2 Positive scoring criteria for SMAD7 immunohistochemistry

\begin{tabular}{l|l|l|l}
\hline $\begin{array}{l}\text { Positive cell } \\
\text { rate (\%) }\end{array}$ & Grade/score & $\begin{array}{l}\text { Average } \\
\text { absorbance }\end{array}$ & Grade/score \\
\hline$\leq 10$ & 0 & $\leq 0.1$ & 0 \\
$10-20$ & 1 & $0.1-0.2$ & $\mathrm{I}$ \\
$20-50$ & 2 & $0.2-0.3$ & 2 \\
$50-75$ & 3 & $\geq 3$ & 3 \\
$\geq 75$ & 4 & & \\
\hline
\end{tabular}


and $X=0-2$ was classified as negative expression, $X=3-5$ as weakly positive expression, $\mathrm{X}=6-8$ as positive expression, and $\mathrm{X}=9-12$ as strongly positive expression.

\section{Cell culture and transfection}

The human NSCLC cell line A549 (Cell bank of Chinese Academy of Sciences, Shanghai, People's Republic of China), an adenocarcinomic human alveolar basal epithelial cell line, was cultured in DMEM (Hyclone, GE Healthcare, Buckinghamshire, UK) $+10 \%$ FBS (Gibco, San Diego, CA, USA) at $37^{\circ} \mathrm{C}$ with $5 \% \mathrm{CO}_{2}$. Cells were passaged 1 day before transfection at the ratio of $1: 3$ (the cell density was preferentially $70 \%-90 \%$ on the next day). Lip2000 (Thermo Fisher Scientific Inc., Waltham, MA, USA) was used to transfect the double-stranded MiR-215p-inhibitor/mimic RNA (MiR-21-5p-NC; Guangzhou Ruibo Biological Company, Guangzhou, People's Republic of China) into A549 cells, which could be used for the following experimental procedures 24-48 hours after transfection.

The expression level of MiR-21-5p in the human NSCLC cell line A549 transfected with or without MiR-215p-inhibitor/mimic RNA (MiR-21-5p-NC) was detected by the miRNA-qPCR kit (GeneCopoeia Inc, Germantown, MD, USA) and a real-time fluorescence quantitative PCR instrument (Agilent Technologies). Relative expression was calculated on the basis of an $\Delta \Delta \mathrm{Ct}$ method.

In addition, in order to determine whether $\operatorname{smad} 7$ was a target of MiR-21-5p, a putative single copy of miR-21-recognition element from the 3 '-UTR of the smad7 gene was cloned downstream of the dual luciferase reporter gene of the GV306 plasmid vector (Genechem, Shanghai, People's Republic of China) to construct the reporter vector SMAD7-WT. In addition, a mutant construct - SMAD7-MUT - was created by converting the MiR-21-5p seed-region-binding site from 5'-TATTCGAT-3' to 5'-CGTGAGCT-3'. SMAD7-WT or SMAD7-MUT was co-transfected with MiR-21-5p-inhibitor or miR-21 overexpression plasmid (MiR-21-5p-NC) into the cells using Lip2000, and a nontargeting negative control RNA was used as the control. At 24-48 hours post transfection, cells were lysed and assayed for luciferase activity with a dual luciferase reporter assay kit (Promega, Madison, WI, USA).

\section{Western blotting assay}

Total proteins were extracted with a total tissue protein extraction kit (Beyotime Biotechnology, Haimen, People's Republic of China) from tissue samples or with a total cell protein extraction kit (Beyotime Biotechnology, Haimen, People's Republic of China) from cells, and the protein concentrations were detected with a BCA kit (Beyotime Biotechnology). In total, $75 \mu \mathrm{g}$ protein from each sample was subjected to SDS-PAGE, then blocked and stained with primary/secondary antibodies. ImageJ software was used to analyze the gray value of protein bands, and the relative expression of the target protein was characterized by the gray value of the target protein band/the gray value of the GAPDH protein band.

\section{Cell colony formation assay}

A549 cells were plated into six-well plates at the concentration of $2 \times 10^{3}$ cells $/ \mathrm{mL}$, and the culture medium was replaced every 3 days. Culture was stopped and the medium was removed when the cell colonies were visible to the naked eye. Cells were rinsed twice with $1 \times$ PBS before fixed with $4 \%$ formaldehyde for 15 minutes. Then, $0.25 \%$ crystal violet was used to stain the cells for 25 minutes after removing the formaldehyde. Sterile water was used to rinse the cells gently before the cells were dried, photographed, and counted.

\section{Cell scratch assay}

A549 cells were plated into six-well plates at a concentration of $2.5 \times 10^{5}$ cells $/ \mathrm{mL}$. After the cells reached confluence, a $10-\mu \mathrm{L}$ white pipette tip was used to scratch the cells vertically to get a cell-free straight line. Then, $1 \times$ PBS was used to rinse off the castoff cells, and FBS-free culture medium was used to culture the cells for 24 hours before they were photographed.

\section{Transwell assay}

A549 cells were passaged in the ratio of 1:2 and, on the next day, FBS-free DMEM was used to culture the cells for another 24 hours. Cells were digested and resuspended in FBS-free DMEM at a concentration of $1 \times 10^{5}$ cells $/ \mathrm{mL}$. In total, $200 \mu \mathrm{L}$ of the cell suspension was added into the pre-hydrated upper Transwell chamber (Chemi-Con, Costar, Cambridge, MA, USA), and $500 \mu \mathrm{L}$ of the cell suspension and $55 \mu \mathrm{L}$ FBS were added into the lower chamber. After 48 hours of regular culture, cells were fixed, stained, dried, and counted.

\section{Statistical analysis}

SPSS 20.0 software was used to analyze the data obtained in this study. A Student's $t$-test was used to compare the measurement data whereas the chi-squared test was used to compare the enumeration data between groups. $P<0.05$ was considered indicative of statistical significance.

\section{Results Clinical data of the II 8 cases of NSCLC patients}

There were 72 male and 46 female in the 118 cases of NSCLC patients, and the average age was 57.85 ( $\mathrm{SD} \pm 7.38$ ) years. 
In these patients, 42 had squamous cell carcinoma and 76 had adenocarcinoma. There were 22 patients with well differentiation, 39 with moderate differentiation, and 57 with poor differentiation of the tumor cells. Lymph node metastasis was found in 73 patients, and distal metastasis in 69 patients. Other general data are shown in Table 1.

\section{Relationship between the expression of MiR-2I-5p and the clinical data}

The relative expression of MiR-21-5p in the 118 cases of NSCLC tumor tissues was (18.53 \pm 3.66$)$. The median of the fold changes in MiR-21-5p expression between tumor tissues and the adjacent normal tissues was 18, which was used to differentiate a low or high expression of MiR-21-5p. In the tumor tissues, there were 75 cases with high expression of MiR-21-5p (relative expression $\geq 18$ ) and 43 with low expression (relative expression $<18$ ). We analyzed the relationship between MiR-21-5p expression and the age, gender, or clinical pathology. The results showed that the expression of MiR-21-5p in NSCLC tumor tissues was unrelated to age $\left(\chi^{2}=0.770, P=0.380\right)$ or gender $\left(\chi^{2}=1.554\right.$, $P=0.213)$, whereas it was correlated with clinical classification $\left(\chi^{2}=7.154, P=0.007\right)$, tumor size $\left(\chi^{2}=4.372, P=0.037\right)$, degree of differentiation $\left(\chi^{2}=13.713, P=0.001\right)$, lymph node metastasis $\left(\chi^{2}=5.101, P=0.024\right)$, distal metastasis $\left(\chi^{2}=12.599\right.$, $P=0.000)$, and TNM staging $\left(\chi^{2}=6.344, P=0.012\right)$, as shown in Table 3.

In addition, SMAD7 protein expression in the 118 cases of NSCLC tumor tissues was detected and scored by immunohistochemistry, and the results showed that there were 6 cases with negative expression, 20 cases with weakly positive expression, 45 cases with positive expression, and 47 cases of strongly positive expression of SMAD7 protein (Figure 1A). The results of Western blotting analysis showed increasing expression of SMAD7 protein among different groups (Figure 1B). SMAD7 expression was significantly correlated with the expression of MiR-21-5p $\left(\chi^{2}=14.669\right.$, $P=0.003)$. Pearson correlation analysis showed that MiR21-5p expression was positively correlated with SMAD7 protein expression $(r=0.669, P<0.05)$, as shown in Table 3 and Figure $2 \mathrm{~A}$ and $\mathrm{B}$.

\section{Relationship between the expression of MiR-2I-5p and the prognosis of NSCLC patients}

All of the patients were followed up for 2 years after surgery, and the postoperative survival of these patients was recorded. The results showed that the 1- and 2-year survival rates of NSCLC patients with low expression of MiR-21-5p
Table 3 Relationship between MiR-2I-5p expression and the clinical data of NSCLC patients

\begin{tabular}{|c|c|c|c|c|}
\hline \multirow[t]{2}{*}{ Item } & \multicolumn{2}{|c|}{ MiR-2I-5p (n) } & \multirow[t]{2}{*}{$\chi^{2}$} & \multirow[t]{2}{*}{$P$-value } \\
\hline & $\begin{array}{l}\text { High } \\
\text { expression }\end{array}$ & $\begin{array}{l}\text { Low } \\
\text { expression }\end{array}$ & & \\
\hline \multicolumn{5}{|l|}{ Gender } \\
\hline Male & 48 & 24 & 0.770 & 0.380 \\
\hline Female & 27 & 19 & & \\
\hline \multicolumn{5}{|l|}{ Age (years) } \\
\hline$\geq 60$ & 35 & 15 & 1.554 & 0.213 \\
\hline$<60$ & 40 & 28 & & \\
\hline \multicolumn{5}{|l|}{ Clinical classification } \\
\hline $\begin{array}{l}\text { Squamous cell } \\
\text { carcinoma }\end{array}$ & 20 & 22 & 7.154 & 0.007 \\
\hline Adenocarcinoma & 55 & 21 & & \\
\hline \multicolumn{5}{|l|}{ Tumor size $(\mathrm{cm})$} \\
\hline$\leq 5$ & 27 & 24 & 4.372 & 0.037 \\
\hline$>5$ & 48 & 19 & & \\
\hline \multicolumn{5}{|l|}{$\begin{array}{l}\text { Degree of } \\
\text { differentiation }\end{array}$} \\
\hline Well differentiated & 8 & 14 & 13.713 & 0.001 \\
\hline $\begin{array}{l}\text { Moderately } \\
\text { differentiated }\end{array}$ & 22 & 17 & & \\
\hline $\begin{array}{l}\text { Poorly } \\
\text { differentiated }\end{array}$ & 45 & 12 & & \\
\hline \multicolumn{5}{|l|}{ Lymph node } \\
\hline \multicolumn{5}{|l|}{ metastasis } \\
\hline Metastasis & 52 & 21 & 5.101 & 0.024 \\
\hline No metastasis & 23 & 22 & & \\
\hline \multicolumn{5}{|l|}{ Lymph node } \\
\hline \multicolumn{5}{|l|}{ metastasis } \\
\hline Metastasis & 53 & 16 & 12.599 & 0.000 \\
\hline No metastasis & 22 & 27 & & \\
\hline \multicolumn{5}{|l|}{ TNM stage } \\
\hline$I+I I$ & 18 & 20 & 6.344 & 0.012 \\
\hline III+IV & 57 & 23 & & \\
\hline \multicolumn{5}{|l|}{ SMAD7 expression } \\
\hline Negative & 0 & 6 & 14.669 & 0.003 \\
\hline Weak positive & 12 & 8 & & \\
\hline Positive & 27 & 18 & & \\
\hline Strong positive & 36 & 11 & & \\
\hline
\end{tabular}

were $83.72 \%$ and $67.44 \%$, respectively, whereas the 1 - and 2-year survival rates of NSCLC patients with high expression of MiR-21-5p were $72.00 \%$ and $50.67 \%$, respectively. Therefore, the survival rate of NSCLC patients with low expression of MiR-21-5p was better than that of the patients with high expression of MiR-21-5p, although no statistical difference was found (1-year survival rate, $\chi^{2}=2.075$, $P=0.150$; 2-year survival rate, $\chi^{2}=3.134, P=0.077$; Figure 3).

\section{Targeted regulation of SMAD7 gene expression by MiR-2I-5p}

The level of MiR-21-5p expression was significantly elevated after the cells were transfected with an miR-21 overexpression plasmid (MiR-21-5p-NC) and significantly decreased 
A
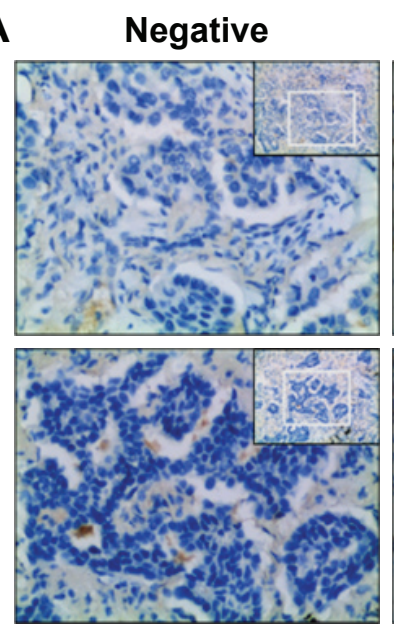

B
Weak positive
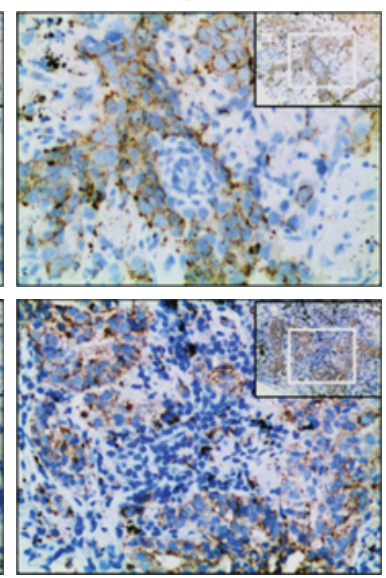

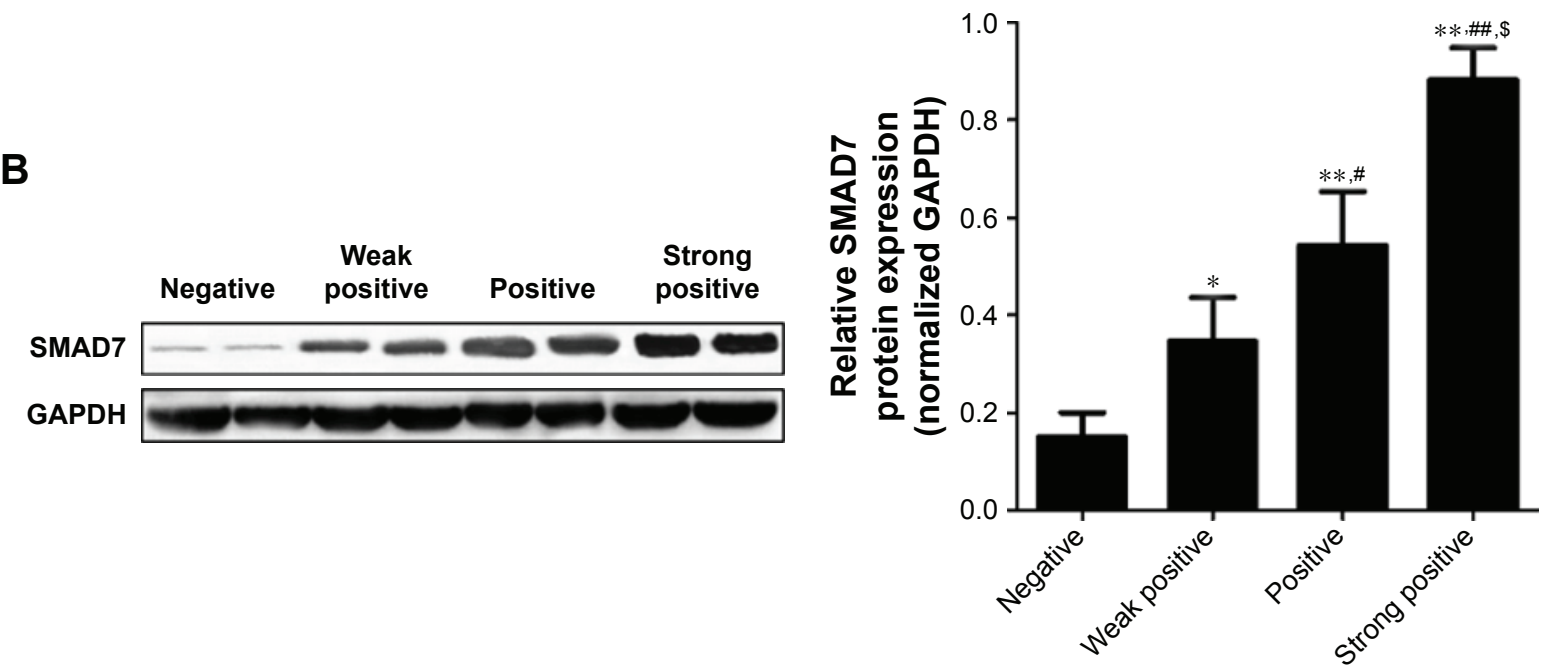

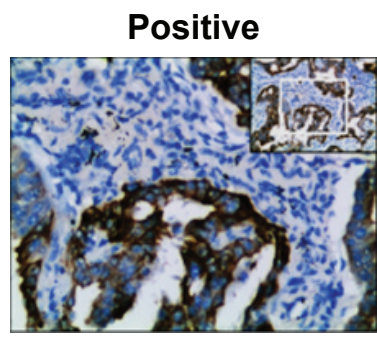

Strong positive
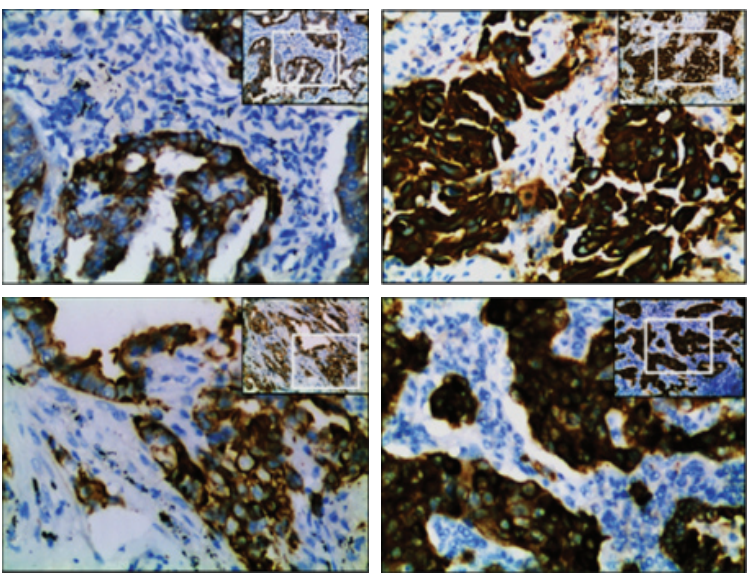

Figure I Expression of SMAD7 in NSCLC tumor tissues.

Notes: (A) Immunohistochemistry of SMAD7 in the tumor tissues of different NSCLC patients. (B) Results of Western blotting of SMAD7 expression in the tumor tissues of different NSCLC patients. ${ }^{*} P<0.05,{ }^{*} * P<0.01$ compared with negative; ${ }^{*} P<0.05,{ }^{*} P<0.01$ compared with weakly positive; and ${ }^{\$} P<0.05$ compared with positive.
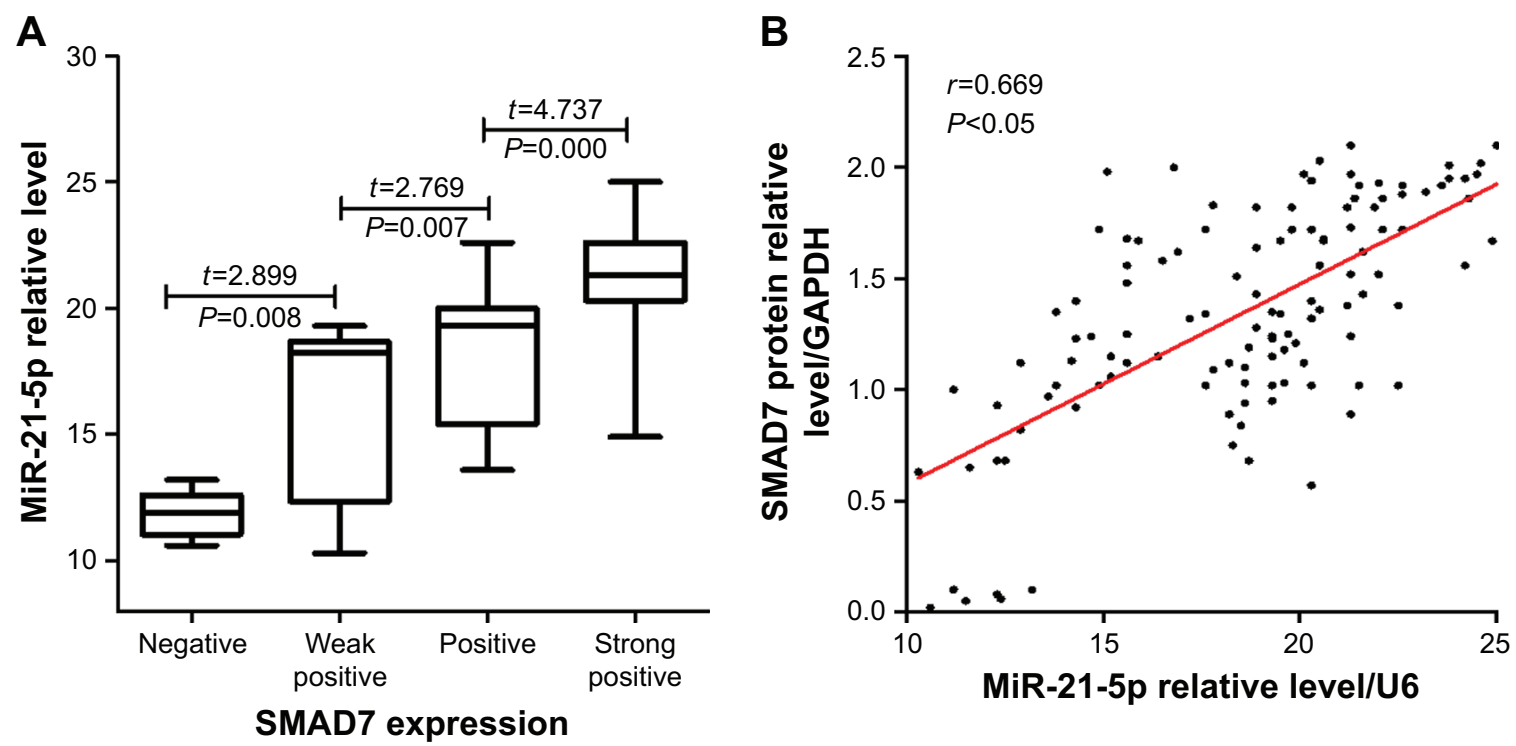

Figure 2 MiR-2I-5p in NSCLC tumor tissues promoted the expression of SMAD7 protein.

Notes: (A) SMAD7 expression is correlated with the expression of MiR-2I-5p. (B) Pearson correlation analysis shows that MiR-2I-5p expression is positively correlated with SMAD7 protein expression $(r=0.669, P<0.05)$. 


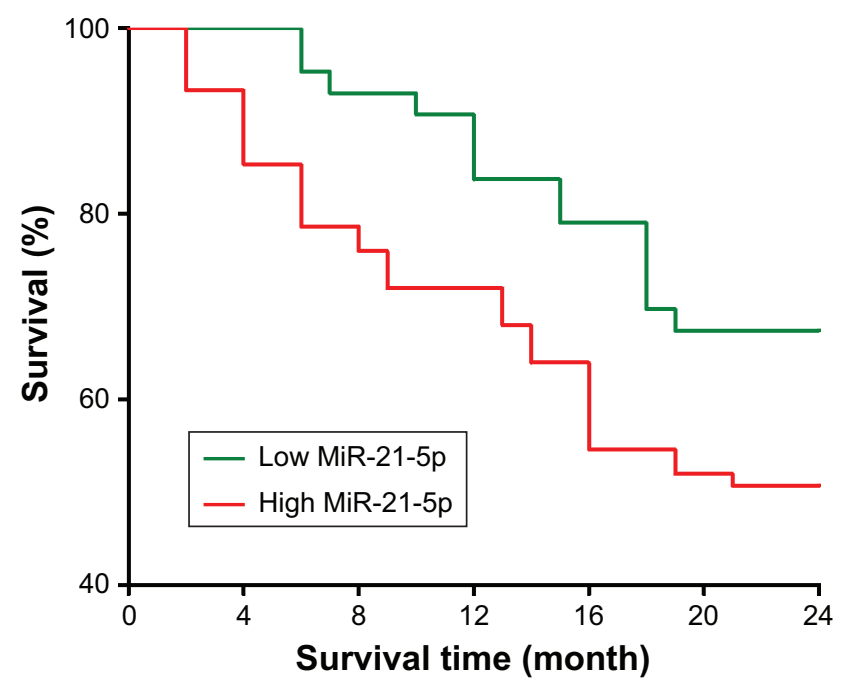

Figure 3 MiR-2I-5p expressions and the postoperative survival rate of NSCLC patients.

Notes: This curve is a description of the survival rate at different time points during a 2-year follow-up of the patients. The I- and 2-year survival rates of the patients were calculated and compared between patients with low vs high MiR$21-5 p$ expression. The results showed no statistically significant differences (I-year survival rate, $\chi^{2}=2.075, P=0.150 ; 2$-year survival rate, $\chi^{2}=3$.134, $P=0.077$ ).

after the cells were transfected with an MiR-21-5p-inhibitor as compared with controls $(P<0.001, P<0.05$, respectively; Figure 4A). The target genes of MiR-21-5p were predicted by bioinformatics methods, and the results showed that there was a complementary sequence with MiR-21-5p on the $3^{\prime}$-UTR end of SMAD7 mRNA, as shown in Figure 4B. The luciferase gene reporter system was used to validate the bioinformatics analysis: transfection of MiR-21-5p-inhibitor could significantly reduce the luciferase activity of wild-type (WT) SMAD7 mRNA 3'-UTR $(P<0.05)$, whereas it did not significantly affect the mutant (MUT), as shown in Figure 4C.
In addition, transfection of the MiR-21-5p-inhibitor could significantly reduce the expression of SMAD7 protein in A549 cells $(P<0.05)$, as shown in Figure 4D.

\section{MiR-2I-5p promoted the proliferation of NSCLC cells}

The effect of MiR-21-5p expression on the proliferation of A549 cells was detected by a cell-cloning experiment. The results indicated that a higher expression of MiR-21-5p was associated with a larger number of A549 cell clones formation - that is, a stronger proliferation ability of A549 (Figure 5). Thus, MiR-21-5p promoted the invasion/migration of NSCLC cells.

A cell scratch test was used to compare the effect of MiR-21-5p expression on the migration ability of A549 cells. The results showed that a higher expression of MiR21-5p was associated with a larger number of migrated cells, suggesting a stronger migration ability of A549 cells (Figure 6A). Transwell assay was used to compare the effect of MiR-21-5p expression on the invasion of A549 cells. The results showed that a higher expression of MiR-21-5p was associated with the invasion of a larger number of A549 cells from the upper chamber into the lower chamber, suggesting a stronger invasion ability of A549 cells (Figure 6B). Epithelial-mesenchymal transition (EMT), which refers to the epithelial cells transforming through specific procedures into mesenchymal cell biological processes, is of pathological significance in carcinogenesis and metastasis in malignant tumors. The expressions of EMT-related proteins were detected by Western blotting in this study. The results suggested that, with the increased expression of MiR-21-5p,
A

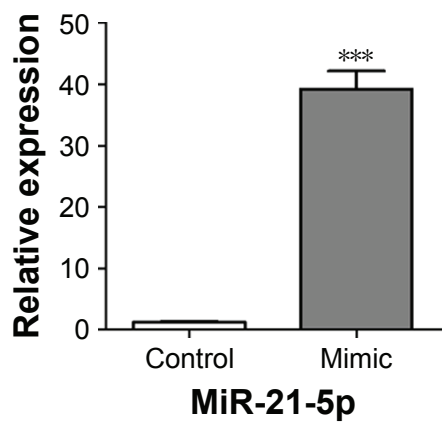

B Position 1122-1129 of SMAD7 3'-UTR 5'

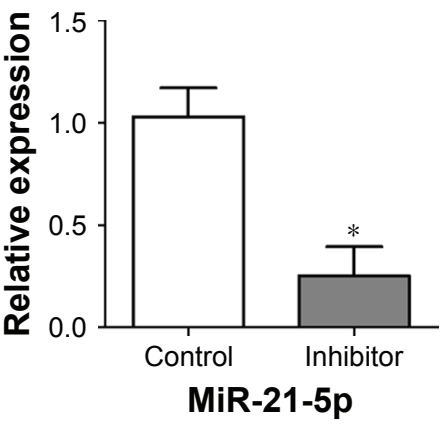

...UGUUUAGACUUUAAC-AUAAGCUA ... 

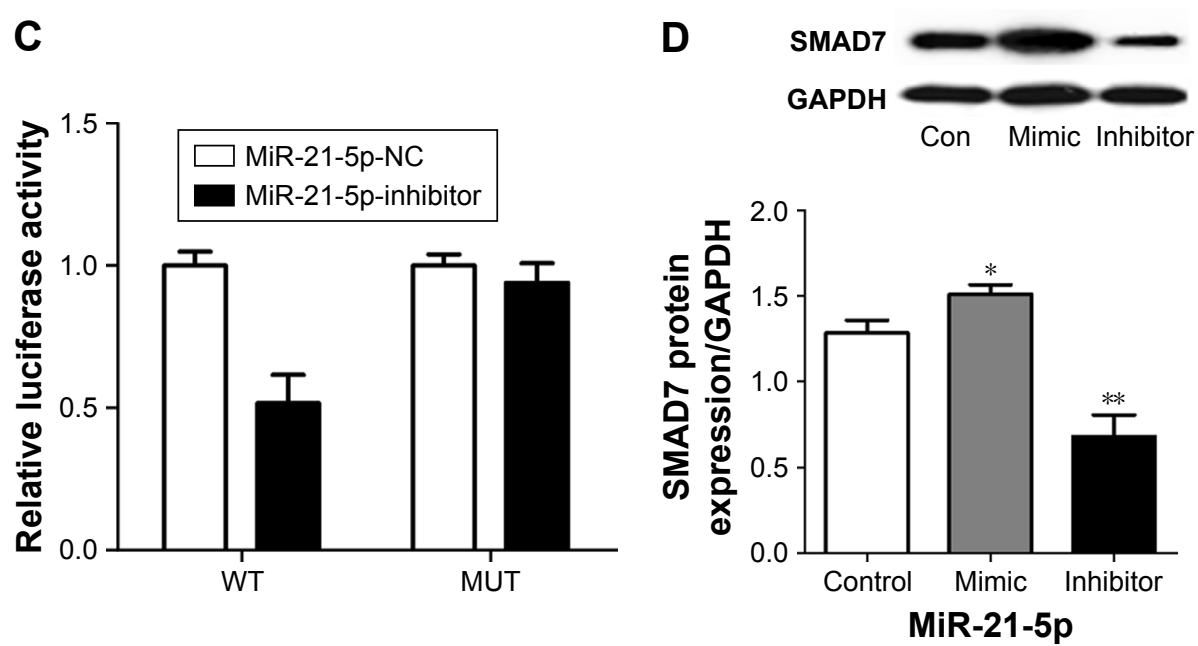

Figure 4 Targeted regulation of SMAD7 gene expression by MiR-2I-5p in A549 cells.

Notes: (A) The level of MiR-2I-5p expression was significantly elevated after the cells transfected with an miR-2I overexpression plasmid (MiR-2I-5p-NC), and significantly decreased after the cells were transfected with a MiR-2I-5p-inhibitor compared with controls. (B) SMAD7 mRNA 3'-UTR has a sequence complementary to MiR-2I-5p. (C) Luciferase reporter system showed that MiR-21-5p targeted SMAD7 gene expression. (D) Expression of SMAD7 protein was detected by Western blotting. *P $<0.05$, $* * P<0.01$, and $* * * P<0.001$ compared with control.

expressions of matrix metalloproteinase-9 (MMP-9) and vimentin protein in A549 cells were upregulated, whereas that of E-cadherin was downregulated (Figure 6C).

\section{Discussion}

MiR-21-5p is located on the human chromosome 17q23.1, which is often abnormally expressed in patients with malignant tumors, such as gastric cancer, ${ }^{10}$ rectal cancer, ${ }^{11}$ and renal cell carcinoma. ${ }^{12}$ It is not only a predictive marker for disease diagnosis and prognosis for patients with gastric cancer, ${ }^{10}$ myasthenia gravis, ${ }^{13}$ renal cell carcinoma, ${ }^{12}$ and thymic epithelial tumor, ${ }^{14}$ but also related to chemotherapy efficacy in patients with rectal cancer ${ }^{11}$ as well as the renal survival rate of patients with nephropathy. ${ }^{15}$ In this study,
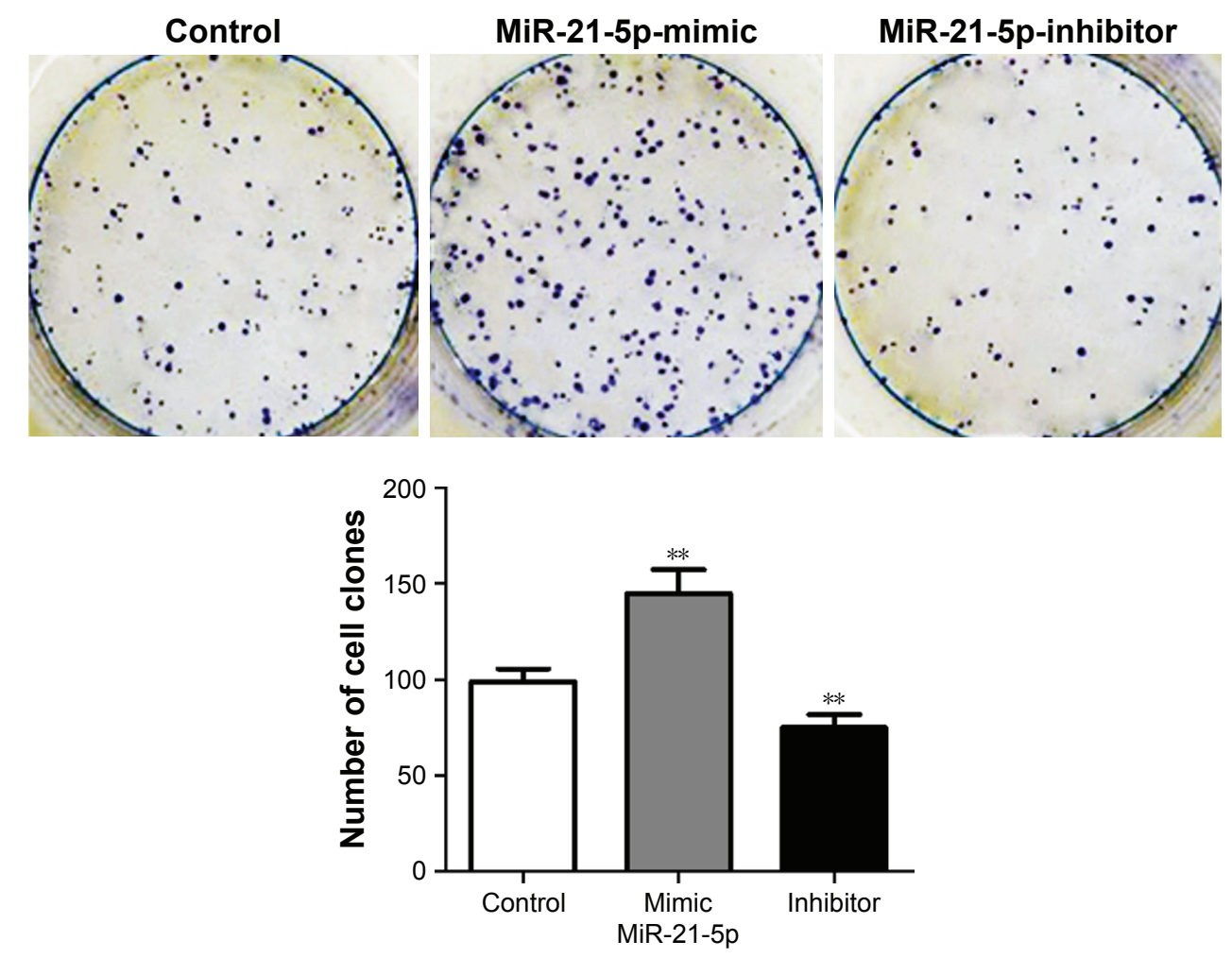

Figure 5 MiR-2I-5p promoted the proliferation of NSCLC cells. Cell-cloning assay was used to detect the effect of MiR-2I-5p expression on the proliferation of NSCLC cells. Note: $* * P<0.01$. 
A
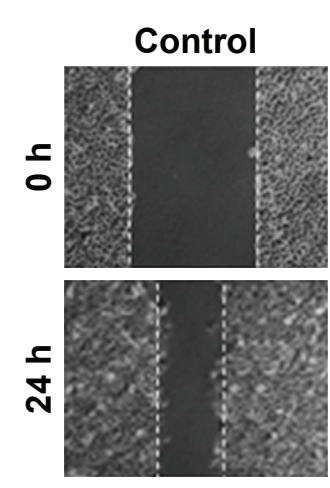

MiR-21-5pmimic
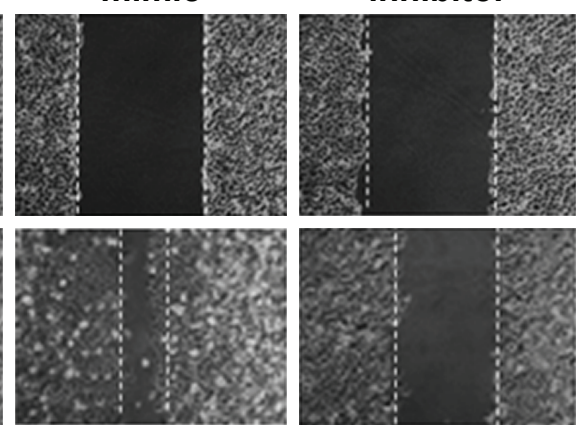

B

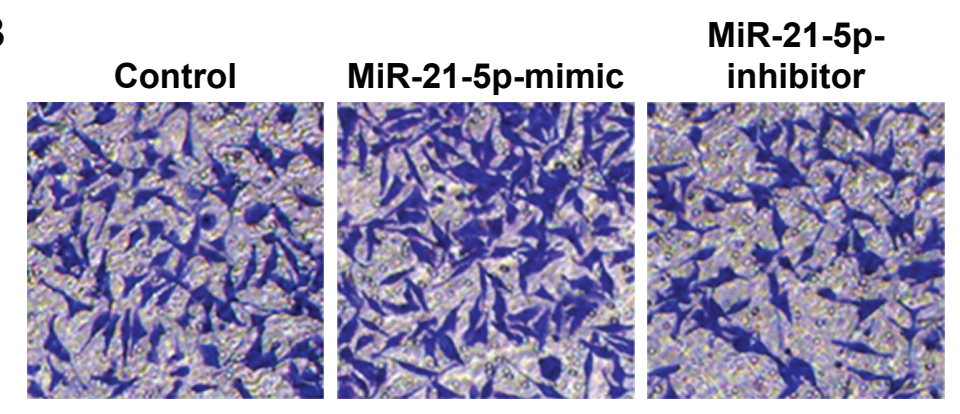

C

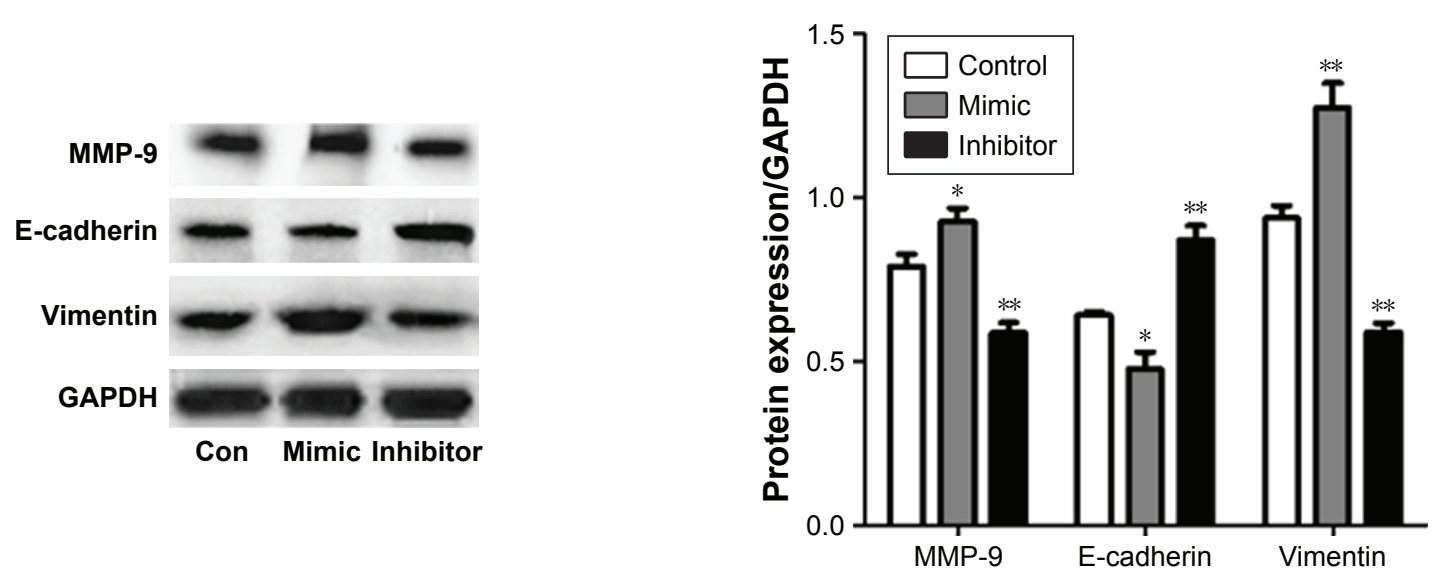

Figure 6 MiR-21-5p promoted the invasion/migration of NSCLC cells.

Notes: (A) A higher expression of MiR-2I-5p was associated with a stronger migration ability of A549 cells. (B) A higher expression of MiR-2I-5p was associated with a stronger invasion ability of A549 cells. (C) Detection of EMT-related protein expressions (MMP-9, E-cadherin, and vimentin). $* P<0.05$ and $* * P<0.0$ I compared with control.

we found that MiR-21-5p was highly expressed in NSCLC tumor tissues, which was consistent with the bioinformatics predictions. ${ }^{9}$ Further analysis of the relationship between the expression of MiR-21-5p and the clinical data of NSCLC patients showed that the expression of MiR-21-5p in tumor tissues of NSCLC patients was significantly correlated with the clinical classification of NSCLC, tumor size, differentiation degree, lymph node metastasis, distant metastasis, and
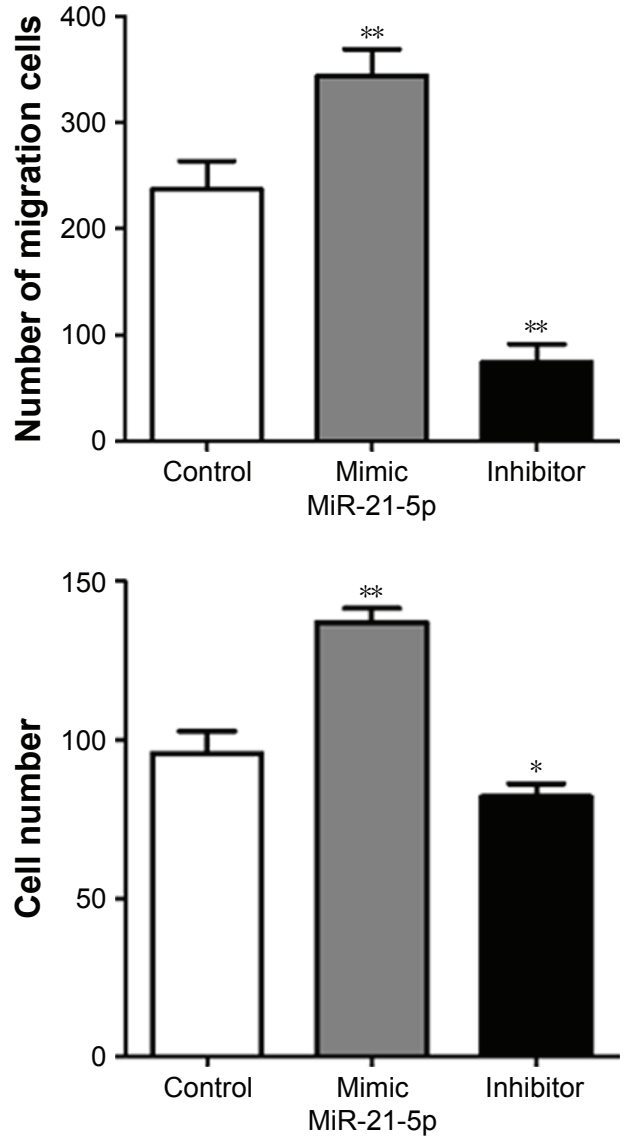
in the cytoplasm. SMAD7 protein is highly expressed in a variety of malignant tumors, and the high expression of SMAD7 can cooperate with TGF- $\beta 1$ and dendritic cells to promote the progression of liver metastasis of rectal cancer. ${ }^{16}$ Moreover, it promotes the progression of endometrial cancer by inhibiting the TGF- $\beta$ signaling pathway. ${ }^{17}$ Therefore, SMAD7 is considered an oncogene. ${ }^{18}$ In combination with the results in this study, we hypothesized that the high expression of MiR-21-5p in NSCLC may promote the progression of NSCLC by targeting the expression of SMAD7 protein. Cell colony formation assay confirmed that MiR-21-5p can promote the proliferation of NSCLC cells. The ability of cell proliferation is related to the cell cycle, and the regulation of the cell cycle is mainly achieved by the retention of the G1 phase. In the G1 phase, there is an important moment of cycle regulation - the restriction point ( $\mathrm{R}$ point). After passage through the R point, cell growth and proliferation become completely autonomous, and is no longer regulated by external cytokines. Cyclin D1 is a protein that promotes cells to passage through the R point. Under normal physiological conditions, the cyclin D1 protein is commonly degraded when the cells enter the $\mathrm{S}$ phase; thus, it maintains a low or negative expression state in healthy cells. However, in cancer cells, cyclin D1 maintains a high expression level and promotes cancer cells to passage through the R point, thus accelerating the growth and proliferation of cancer cells. ${ }^{19}$ Previous studies ${ }^{20}$ indicated that SMAD7 can promote the expression of cyclin D1 protein as well as the proliferation of cancer cells by inhibiting the TGF- $\beta$ signaling pathway and, finally, induce tumorigenicity.

Cell migration and Transwell experiments confirmed that MiR-21-5p can promote the invasion/migration ability of NSCLC cells, as well as the expression of MMP-9 and vimentin proteins while inhibiting the expression of the E-cadherin protein. MMP-9, vimentin, and E-cadherin are three genes that have been confirmed to play important roles in EMT, which confers the ability of metastasis and invasion on cells. For tumor cells, the promotion of tumor cell EMT can inhibit the expression of intercellular junction proteins, resulting in the decrease of the mutual binding force between cells, which is conducive to the invasion and migration of tumor cells into surrounding healthy tissues. ${ }^{21} \mathrm{MMP}-9$ is an important enzyme in the matrix metalloproteinase (MMP) family. Studies have shown that MMPs are the most important proteolytic enzymes in the process of EMT, and upregulation of MMP-9 protein expression can enhance the invasion/migration ability of tumor cells. The vimentin protein is mainly expressed in mesenchymal cells, and its high expression is a critical marker for EMT, ${ }^{22}$ which is also closely related to lymph node metastasis, clinical stage, and prognosis of lung cancer. ${ }^{23}$ The function of the E-cadherin protein in the process of tumor cell EMT is opposite to that of MMPs and vimentin proteins. E-cadherin provides a mutual adsorption between cells as well as between cells and substances of the basement membrane. As an epithelial marker in the EMT process, E-cadherin can inhibit the migration of tumor cells. The migration and invasion abilities of tumor cells will be enhanced when the expression of the E-cadherin protein is decreased. ${ }^{24}$ Furthermore, previous studies ${ }^{18,25}$ showed that SMAD7 promoted the invasion/migration ability of the tumor cells through EMT. In this study, MiR-21-5p promotes the expressions of MMP-9 and vimentin proteins as well as inhibits the expression of the E-cadherin protein, which is associated with an elevated SMAD7 protein expression, and enhances the invasion/migration ability of NSCLC cells.

In conclusion, MiR-21-5p is highly expressed in NSCLC tumor tissues, which may promote the progression of NSCLC by targeting and promoting the expression of SMAD7.

\section{Acknowledgments}

This research was supported by the Hubei Provincial Health and Family Planning Commission Foundation (grant no WJ2017M027) and Hubei Province Natural Science Foundation (grant no 2014CFB394).

\section{Disclosure}

The authors report no conflicts of interest in this work.

\section{References}

1. Chen W, Zheng R, Baade PD, et al. Cancer statistics in China, 2015. CA Cancer J Clin. 2016;66(2):115-132.

2. Chen W, Zheng R, Zeng H, Zhang S. Epidemiology of lung cancer in China. Thorac Cancer. 2015;6(2):209-215.

3. Shi J, Zhu J. Health Resource Utilization in Patients with Advanced Non-Small Cell Lung Cancer Receiving Chemotherapy in China. Clin Drug Investig. 2016;36(1):77-86.

4. Qiu G, Fang B, Xin G, Wei Q, Yuan X, Wu D. miR-25 promotes cell proliferation by targeting RECK in human cervical carcinoma HeLa cells. Xi Bao Yu Fen Zi Mian Yi Xue Za Zhi. 2015;31(1):40-43.

5. Cao $\mathrm{Y}$, Wang $\mathrm{P}$, Ning $\mathrm{S}$, et al. Identification of prognostic biomarkers in glioblastoma using a long non-coding RNA-mediated, competitive endogenous RNA network. Oncotarget. 2016;7(27):41737-41747.

6. Wang J, Chen J, Sen S. MicroRNA as Biomarkers and Diagnostics. $J$ Cell Physiol. 2016;231(1):25-30.

7. Wang Y, Xu L, Jiang L. miR-1271 promotes non-small-cell lung cancer cell proliferation and invasion via targeting HOXA5. Biochem Biophys Res Commun. 2015;458(3):714-719.

8. Ye M, Zhang J, Zhang J, et al. Curcumin promotes apoptosis by activating the $\mathrm{p} 53$-miR-192-5p/215-XIAP pathway in non-small cell lung cancer. Cancer Lett. 2015;357(1):196-205.

9. Yang C, Sun C, Liang X, et al. Integrative analysis of microRNA and mRNA expression profiles in non-small-cell lung cancer. Cancer Gene Ther. 2016;23(4):90-97.

10. Park SK, Park YS, Ahn JY, et al. MiR 21-5p as a predictor of recurrence in young gastric cancer patients. J Gastroenterol Hepatol. 2016;31(8): $1429-1435$. 
11. Lopes-Ramos CM, Habr-Gama A, Quevedo BS, et al. Overexpression of miR-21-5p as a predictive marker for complete tumor regression to neoadjuvant chemoradiotherapy in rectal cancer patients. BMC Med Genomics. 2014;7(1):68.

12. Kowalczyk AE, Krazinski BE, Godlewski J, et al. SATB1 is Downregulated in Clear Cell Renal Cell Carcinoma and Correlates with miR-21-5p Overexpression and Poor Prognosis. Cancer Genomics Proteomics. 2016;13(3):209-217.

13. Punga AR, Andersson M, Alimohammadi M, Punga T. Disease specific signature of circulating miR-150-5p and miR-21-5p in myasthenia gravis patients. J Neurol Sci. 2015;356(1-2):90-96.

14. Bellissimo T, Russo E, Ganci F, et al. Circulating miR-21-5p and miR-148a-3p as emerging non-invasive biomarkers in thymic epithelial tumors. Cancer Biol Ther. 2016;17(1):79-82.

15. Hennino MF, Buob D, van der Hauwaert C, et al. miR-21-5p renal expression is associated with fibrosis and renal survival in patients with IgA nephropathy. Sci Rep. 2016;6:27209.

16. Chun HK, Jung KU, Choi YL, et al. Low expression of transforming growth factor beta-1 in cancer tissue predicts a poor prognosis for patients with stage III rectal cancers. Oncology. 2014;86(3):159-169.

17. Dowdy SC, Mariani A, Reinholz MM, et al. Overexpression of the TGF-beta antagonist Smad7 in endometrial cancer. Gynecol Oncol. 2005;96(2):368-373.

18. Luo L, Li N, Lv N, Huang D. SMAD7: a timer of tumor progression targeting TGF- $\beta$ signaling. Tumour Biol. 2014;35(9):8379-8385.
19. Burandt E, Grünert M, Lebeau A, et al. Cyclin D1 gene amplification is highly homogeneous in breast cancer. Breast Cancer. 2016;23(1): 111-119.

20. Halder SK, Beauchamp RD, Datta PK. Smad7 induces tumorigenicity by blocking TGF-beta-induced growth inhibition and apoptosis. Exp Cell Res. 2005;307(1):231-246.

21. Sung WJ, Kim H, Park KK. The biological role of epithelial-mesenchymal transition in lung cancer (Review). Oncol Rep. 2016;36(3):1199-1206.

22. Lee J, Hahm ER, Marcus AI, Singh SV. Withaferin A inhibits experimental epithelial-mesenchymal transition in MCF-10A cells and suppresses vimentin protein level in vivo in breast tumors. Mol Carcinog. 2015;54(6):417-429.

23. Ye Z, Zhang X, Luo Y, et al. Prognostic Values of Vimentin Expression and Its Clinicopathological Significance in Non-Small Cell Lung Cancer: A Meta-Analysis of Observational Studies with 4118 Cases. PLoS One. 2016;11(9):e0163162.

24. Coopman P, Djiane A. Adherens Junction and E-Cadherin complex regulation by epithelial polarity. Cell Mol Life Sci. 2016;73(18): 3535-3553.

25. Smith AL, Iwanaga R, Drasin DJ, et al. The miR-106b-25 cluster targets Smad7, activates TGF- $\beta$ signaling, and induces EMT and tumor initiating cell characteristics downstream of Six 1 in human breast cancer. Oncogene. 2012;31(50):5162-5171.
OncoTargets and Therapy

\section{Publish your work in this journal}

OncoTargets and Therapy is an international, peer-reviewed, open access journal focusing on the pathological basis of all cancers, potential targets for therapy and treatment protocols employed to improve the management of cancer patients. The journal also focuses on the impact of management programs and new therapeutic agents and protocols on

\section{Dovepress}

patient perspectives such as quality of life, adherence and satisfaction The manuscript management system is completely online and includes a very quick and fair peer-review system, which is all easy to use. Visit http://www.dovepress.com/testimonials.php to read real quotes from published authors. 